\title{
Relationship between Parental Smoking and Children's Pulmonary Function
}

\author{
Trupti Sutaria $^{1}$, Neepa Talati ${ }^{2}$, Apeksha Vaghasiya ${ }^{3}$, Jhalak Prajapati ${ }^{3}$ \\ ${ }^{1}$ Ex. I/C Principal, Ahmedabad Institute of Physiotherapy, Gota, Ahmedabad, Gujarat University \\ ${ }^{2}$ Professor, School of Physiotherapy, PP Savani University, Surat \\ ${ }^{3}$ Assistant Professor, Khyati Institute of Physiotherapy, Shahibaug, Ahmedabad, Gujarat University
}

Corresponding Author: Trupti Sutaria

\begin{abstract}
Purpose: To Study/Understand the Exposureresponse Relationship between Parental Smoking and Children's Pulmonary Function

Materials and Method: Participants were selected randomly who fit into the inclusion criteria. Selected participants to be then made understood for the nature of study. Subjects were asked to seat upright on table / stool facing the Spirometer machine. Spirometer was done with the RMH Helios computerized Spirometer. Subjects were asked use nose clip and exhale complete and maximum air for long duration then immediately take deep inspiration followed by complete and maximum expiration for long time. Out of 3 or 4 manoeuvres the best manoeuvre was selected and \% predicted of $\mathrm{FEV}^{1}$, FVC, FEV 1 /FVC, PEFR, FEF 25 - 75 was documented.
\end{abstract}

Results: Statical analysis was done by using Parametric (unpaired $t$ test) and or nonparametric (Mann Whitney) statical test with $95 \%$ class interval (one tailed p). Spearman's correlation test was obtained to check the relationship between variables.

Conclusion: There is a significant reduction in PEFR due to obstructive effect of parental smoking (passive smoking) on pulmonary function of the children. And with increase in number of packs per years, there is a reduction in $\mathrm{FEV}_{1}, \mathrm{FVC}$, PEFR and $\mathrm{FEF}_{25-75}$ of children.

Keywords: Passive Smoking, Pulmonary

Function, children

\section{INTRODUCTION}

Cigarette smoking is highly prevalent and causes serious health problem globally. ${ }^{1}$ There are approximately 1.1 million smokers worldwide, out of which 182 million of them live in India ${ }^{2}$ Exposure to smoking often begins with maternal smoking in utero. From maternal, household or contacts in community, early life exposure may increase the susceptibility of infant to develop lung disease and reduce lung function. ${ }^{3,}{ }^{4}$ The effects of passive smoking on many pathophysiological mediators of coronary artery disease are nearly as large as those of active smoking, including impaired platelet function, damage to vascular endothelium and its associated repair mechanisms, a rise in inflammatory molecules, and dysfunctional. ${ }^{1}$ Smoking by parents is associated with a wide range of adverse effects in their children which includes exacerbation of asthma, increased frequency of colds, ear infection \& sudden infant death syndrome. ${ }^{5}$

A meta-analysis analysed 79 studies and reported that increased risk of asthma in children by $20-85 \%$ due to exposure to smoking, which shows the significant burden of pulmonary diseases due to exposure to passive smoke during childhood. ${ }^{6}$ According to Wang et al, an annual follow up report on exposure of children and adults, showed that there is decrease in $\mathrm{FEV}_{1}, \mathrm{FEV}_{1} / \mathrm{FVC}$ and FEE $25-75$ of FVC. Another study by $\mathrm{He}$ et al, found deficits in FEF but not in $\mathrm{FEV}_{1}$ and FVC, and effect in FEF might be functional and 
not structural, and due to temporary narrowing. ${ }^{7,8}$

Research on passive smoking provides strong evidence of smoking's negative impact on pulmonary function, but relatively few reports are available, on the effect of parental smoking and its effects on children's lung function.

\section{MATERIALS AND METHOD}

30 Children were randomly selected as per the inclusion and exclusion criteria after finding their suitability. Out of which 15 children whose parents were smoker and 15 children's parents were non-smokers. The inclusion criteria were age $\geq 8$ and $15 \leq$ years, parents were smoker, child has never smoked, any family members except parent have never smoked and coal was not used for either heating of cooking at the home. The exclusion criteria were any known cardio respiratory, musculoskeletal disease mainly involving thorax and upper limb, and neurological conditions. Children and their parents were briefly stated about the nature of study and intervention after their enrolment. Written consent was taken from their parents.

\section{Procedure}

On the day of intervention, physical examination was done and vitals were noted and anthropometric measurements were done with calibrated measure. History of smoking from parents were taken. Subjects were asked to seat upright on table / stool facing the Spirometer machine. Spirometer was done with the RMH Helios computerized Spirometer. Subjects were asked use nose clip and exhale complete and maximum air for long duration then immediately take deep inspiration followed by complete and maximum expiration for long time. Out of 3 or 4 manoeuvres the best manoeuvre was selected and \% predicted of FEV1, FVC, FEV1/FVC, PEFR, FEF25-75 was documented.

\section{Statistical Methods}

The data was analysed using Graph pad Prism. Based on normality appropriate Parametric (unpaired $t$ test) or nonparametric (Mann Whitney) statical tests with $95 \%$ class interval (one tailed p)

\section{RESULT}

Demographic data of Group A and Group B were given in Table 1.

Table 1

\begin{tabular}{|l|c|c|}
\hline \multicolumn{3}{|c|}{ Demographic Data } \\
\hline & $\begin{array}{c}\text { Parental smoking / } \\
\text { Group -B }\end{array}$ & $\begin{array}{c}\text { Control Group / } \\
\text { Group - A }\end{array}$ \\
\hline Total & 15 & 15 \\
\hline Male & 6 & 9 \\
\hline Female & 9 & 6 \\
\hline Age & $12.4 \pm 1.76$ & $11.73 \pm 2.09$ \\
\cline { 1 - 1 } (Mean \pm SD) & & \\
\hline
\end{tabular}

\begin{tabular}{|c|c|c|c|c|c|}
\hline $\begin{array}{c}\text { Parameters } \\
\text { (\% Predicted) }\end{array}$ & $\begin{array}{l}\text { Paternal smoking group } \\
\text { (Mean } \pm \text { SD) }\end{array}$ & $\begin{array}{l}\text { Control group } \\
\text { (Mean } \pm \text { SD) }\end{array}$ & P Value & $\begin{array}{l}\text { Unpaired } \\
\mathbf{t} \text { - value }\end{array}$ & $\begin{array}{l}\text { Significance } \\
\text { (NS / S) }\end{array}$ \\
\hline $\mathrm{FEV}_{1}$ & $76.6 \pm 14.68$ & $80.4 \pm 13.80$ & 0.3099 & 0.501 & NS \\
\hline $\mathrm{FEV}_{1} / \mathrm{FVC}$ & $111.33 \pm 3.74$ & $111.2 \pm 5.29$ & 0.4985 & 0.0037 & NS \\
\hline $\mathrm{FFF}_{25-75}$ & $101.33 \pm 25.22$ & $98.67 \pm 18.68$ & 0.3723 & 0.329 & NS \\
\hline
\end{tabular}

According to Table 2 (a), The mean of difference between Parental smoking group and Control group for FEV1, FEV1 /
FVC and FEF25-75 was analysed by using Unpaired t-test with $95 \%$ of CI. $(p<0.005)$

Table 2(b)

\begin{tabular}{|c|c|c|c|c|c|}
\hline $\begin{array}{c}\text { Parameters \% } \\
\text { Predicted }\end{array}$ & $\begin{array}{c}\text { Paternal smoking group } \\
\text { (Mean } \pm \text { SD) }\end{array}$ & $\begin{array}{c}\text { Control group } \\
\text { (Mean } \pm \text { SD) }\end{array}$ & P Value & $\begin{array}{c}\text { Unpaired t - value } \\
\text { Mean Whitney U (U') }\end{array}$ & $\begin{array}{c}\text { Significance } \\
\text { (NS / S) }\end{array}$ \\
\hline FVC & $68.8 \pm 13.21$ & $72.47 \pm 14.75$ & 0.4505 & $109(116)$ & NS \\
\hline PEFR & $71.6 \pm 14.81$ & $89 \pm 19.50$ & 0.015 & $60(165)$ & S \\
\hline
\end{tabular}

The mean of difference between Parental smoking group and Control group for FVC and PEFR was analysed by using
Mann Whitney U test with 95 \% of CI. (p $<0.005$ ), which shows significant reduction in PEFR in Parental smoking group. 
Table 3

\begin{tabular}{|l|l|}
\hline Pack per Year & Significance \\
\hline Correlation of pack per year with Paternal smoking Group Parameters \% Predicted & r value \\
\hline FEV $_{1}$ & -0.2013 \\
\hline FVC & -0.2453 \\
\hline FEV1 / FVC & 0.2913 \\
\hline PEFR & -0.4291 \\
\hline FEF $_{25-75}$ & -0.0502 \\
\hline
\end{tabular}

Correlation of pack per year with FEV $\mathrm{FEV}_{1}$ FV, FEV 1 / FVC, PEFR and $\mathrm{FEF}_{25}-75$ was analysed by using Spearman's correlation test.

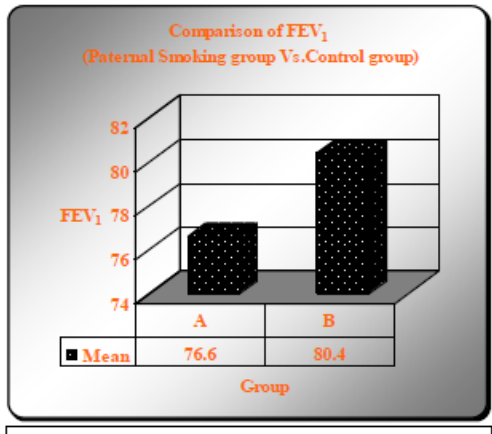

Graph 1: Mean of Control Group and Paternal Smoking Smoking Groub for FEV,

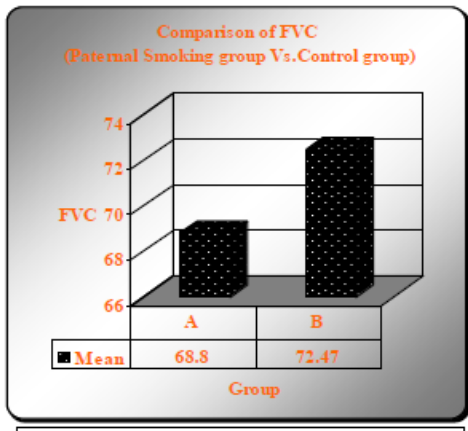

Graph 2: Mean of Control Group and Paternal Smoking Groun for FVC

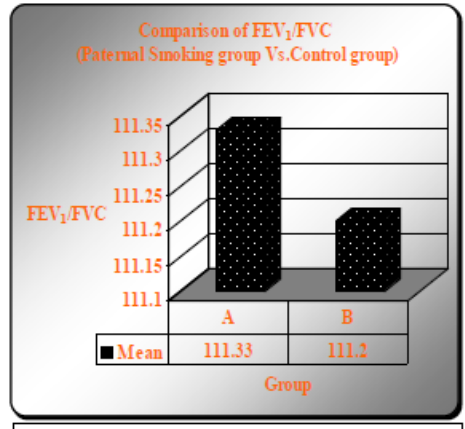

Graph 3: Mean of Control Group and Paternal Smoking Groun for $\mathrm{FEV}_{1} / \mathrm{FVC}$

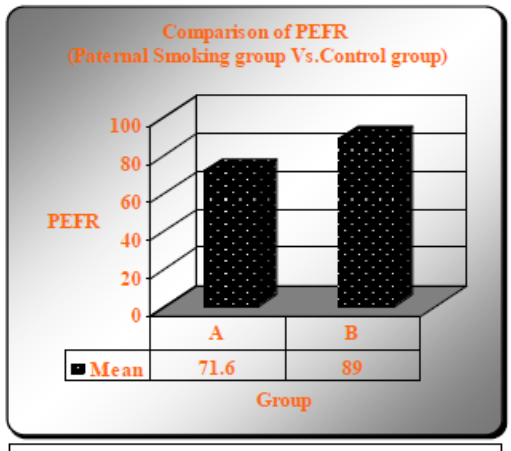

Graph 4: Mean of Control Group and Paternal Smoking Group for PEFR

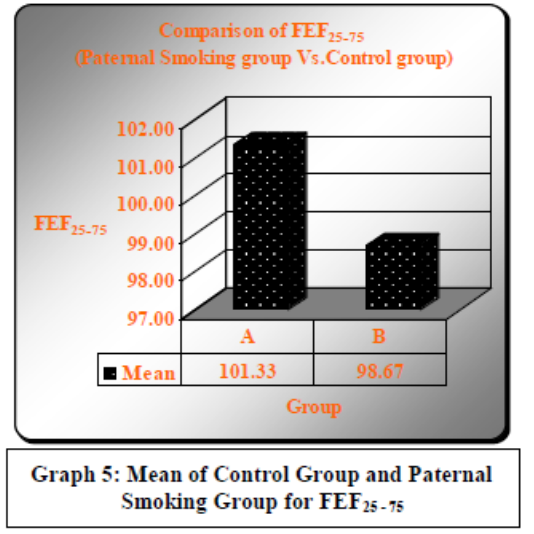

\section{DISCUSSION}

The current study "Relationship between Parental Smoking and Children's pulmonary function" was conducted to access the effect of passive cigarette smoking on lung function of children. Pulmonary function tests in form of office spirometry were performed on total 30 subjects, who were divided into two groups with 15 subjects in each group.15 in Control Group and 15 in paternal smoking Group. All the subjects were in between the age group of $8-15$ years.

The differences in the mean value of FEV 1 , FVC, FEV 1 FVC, PEFR and $\mathrm{FEF}_{25}$ $75 \%$ between Parental smoking group and Control group and the difference in each parameter in Paternal smoking group based on the number of cigarettes smoked per year were analysed.

\section{FEV 1}

In the current study there was no statically significant difference in the mean value of FEV1 $(p=0.3099)$ between the Control Group and Parental Smoking Group. Here correlation of Pack per Year with FEV1was negative ( $\mathrm{r}=-0.2013)$ but not significant.

Above results are also supported per study report of Nuhoglu C, Gurul M et al (2003) conducted their study by taking 33 children, who were exposed to environmental tobacco smoke inside their homes. The $\mathrm{FEV}_{1}, \mathrm{FEV}_{1} / \mathrm{FVC}$ and $\mathrm{FEF}_{25}$ $75 \%$ were found significantly lower than the 
non-smoker control group. ${ }^{8}{ }^{9} \mathrm{Hogg}$ and his colleagues (1994) studied the lung structure and function in cigarette smokers and observed a decline in $\mathrm{FEV}_{1}$ associated with an increase in residual volume and a decrease in diffusing capacity in smokers and concluded that this reduction in $\mathrm{FEV}_{1}$ can be partially explained by loss of lung elastic recoil pressure. ${ }^{10}$ Alan Smyth et al (1994) conducted a study on 57 children with cystic fibrosis and 51 in control group. In cystic fibrosis group, when the parents smoked the child's FEV1 decreased by 4\% and FVC by $3 \%$ for every 10 cigarettes smoked in the house each day. ${ }^{11}$

\section{FVC}

In the current study there was no significant difference in FVC $(\mathrm{p}=0.45)$ between both the group. FVC ( $\mathrm{r}=-0.24)$ was not significant and negatively correlated with the pack year in parental smoking group.

Beijing Respiratory Health Study (1994) on 1,618 male and 1,669 female adults, aged 40-69 yrs found that female smokers had reduced $\mathrm{FEV}_{1}$ and FVC compared with male smokers, after adjusting for smoking year, smoking status, and other related confounding factors. ${ }^{12}$ MMHaby, JK Peat, AJ Woolcock (1994) studied effects on lung function of passive smoking, current asthma, past asthma, and a current respiratory infection with the Children age $8-11$ years. They found that Passive smoking was associated with reduced $\mathrm{FEV}_{1}, \mathrm{PEFR}$, and $\mathrm{FEF}_{25-75} \%$ and FVC was reduced in respiratory infection. ${ }^{13} \mathrm{~A}$ cross sectional study done by Corbo GM et al (2007) to evaluate the effect of parental smoking on lung function of adolescents observed subjects with smoking parents had higher FVC and significant lower $\mathrm{FEV}_{1} / \mathrm{FVC}$ ratios than subjects without smoking parents. ${ }^{14}$

\section{FEV $_{1}$ / FVC}

Mean value of $\mathrm{FEV}_{1} / \mathrm{FVC}$ ( $\mathrm{p}=$ 0.4985 ) there was no statistical difference between control group and parental smoking group. Correlation of $\mathrm{FEV}_{1} / \mathrm{FVC}(\mathrm{r}=$ 0.2913 ) with pack year in parental smoking group was positive and not significant.

According to the Corbo G M (2003) Study done on 441 subjects were found to be heterozygotes. There was a reduction in lung function in sixty-one subjects exposed to parental smoking in the overall sample and $\mathrm{FEV}_{1} / \mathrm{FVC}$ ratio, $\mathrm{FEF}_{25-75}$, and $\mathrm{FEF}_{75}$. In subjects exposed to parental smoking the decrement in lung function in heterozygotes tended to be greater than in homozygotes. ${ }^{15}$ Study by Sherrill DL, Martinez FD (1992) done on children to see the effect of smoke exposer on lung function included age 9-15 years in utero exposure from mothers who smoke during pregnancy, passive smoke from parents, and active smoking by the children. No significant negative effects were seen for absolute $\mathrm{FEV}_{1}$ or FVC in either sex, related to active or passive smoke exposures. Parental smoking was associated with persistent but mild and non-progressive impairment of the $\mathrm{FEV}_{1} / \mathrm{FVC}$ ratio in males. ${ }^{16}$

\section{PEFR}

Mean value of PEFR ( $p=0.015)$ was found to be significant for both the groups and was significantly lower in parental smoking group and there was also negative but non-significant correlation of PEFR ( $\mathrm{r}=-0.4291)$ with pack year in Parental Smoking Group.

Predisposition to airway narrowing and decreased lung recoil may vary between men and women given sex differences in lung characteristics. ${ }^{82}$ In addition, experimental evidence suggests that the distribution of particle deposition in the airways is likely to be more proximal in women compared to men. ${ }^{17}$

Since airway caliber is smaller in size in women, it could be hypothesised that the same reduction in airway diameter would result in a relatively more impact on the reduction in flow rates in women compared to men. ${ }^{18,19}$ KenanBek and Nazan Tomac (1999) studied that Paternal smoking was associated with reduced levels of FEF 
between 25-75\% of vital capacity, PEFR, and flow rates after $50 \%$ and $75 \%$ of vital capacity expired. Maternal smoking did not have statistically significant adverse effects on children's pulmonary function. ${ }^{20}$ Nancy NR et al (1981) done a study found that all outcome measures FEV 1, FVC and $\mathrm{FEV}_{1 / \mathrm{FVC}}$ were not statically significant, but PEFR was statically significant ( $p$ $=0.015$ ) this is because smoking causes inflammation and narrowing of the airways that is going to increase resistance to the airflow. ${ }^{23}$

\section{$\mathbf{F E F}_{25-75}$}

Difference of $\mathrm{FEF}_{25}-75$ ( $\left.\mathrm{p}=0.3723\right)$ between Parental smoking group and control group was found to be nonsignificant for both the group and there was negative correlation of $\mathrm{FEF}_{25}-75$ ( $\mathrm{r}=$ 0.0502) with pack year in Parental smoking group.

Nuhoglu C, Gurul M et al (2003) in their study by taking 33 children who were exposed to environmental tobacco smoke inside their homes, having decrease in $\mathrm{FEF}_{25-75 \%} \%$ was significantly correlated inversely with the number of cigarettes smoked per day.

Mehmet Polatly (2000) studies the early effect of smoking on spirometry and transfer factor of carbon monoxide in asymptomatic smokers. It was carried out in a men (39 non-smokers and 93 smokers) aged 22 to 45 years. A significant correlation was found between smoking pack year and $\mathrm{FEF}_{75} \%$ was found to be under $75 \%$ of the predicted value in 22 smokers with a history of smoking over 20 pack years. So, lower values may indicate the early destruction of the lungs and transfer factor may be used as an additional parameter to spirometry. ${ }^{24}$

Dr. Francisco Javier Gonzalez Barcala (2007) did a cross-sectional study on healthy children and adolescents between 6 and 18 years of age, found that Children whose fathers were smokers presented a $30 \%$ higher risk of reduced FEF25\%-75\% and a Children whose mothers were smokers presented a $30 \%$ higher risk of reduced $\mathrm{FEV}_{1}$.

Finally, children of parental smoking group live in their home with at least one smoker, so every effort should be made to reduce passive exposure to children and give them a chance to grow up in a healthier environment.

\section{CONCLUSION}

The study reveals that there is a significant reduction in PEFR due to obstructive effect of parental smoking (passive smoking) on pulmonary function of the children. With increase in number of packs per years, there is a reduction inFEV $V_{1}$, FVC, PEFR and $\mathrm{FEF}_{25-75}$ of children. Further research with duration of exposure is needed to see the impact of smoking on pulmonary function.

\section{Acknowledgement: None}

\section{Conflict of Interest: None}

\section{Source of Funding: None}

\section{Ethical Approval: Approved}

\section{REFERENCES}

1. Major issues and challenges for tobacco control in south-east Asia, noncommunicable diseases and mental health tobacco free initiative, regional office for south-east Asia, Worldwide health organization, New Delhi 110002, India.

2. Gajalakshmi Ck et al, Global patterns of smoking and smoking attributable mortality. Tobacco-control in developing countries, Oxford University press 2000: P-11 to 39.

3. Martinez FD. The origins of asthma and chronic obstructive pulmonary disease in early life. Proceedings of the American Thoracic Society. 2009; 6:272-277.

4. Wang L, Pinkerton KE. Detrimental effects of tobacco smoke exposure during development on postnatal lung function and asthma. Birth Defects Res C Embryo Today. 2008 Mar;84(1):54-60. doi: 10.1002/bdrc.20114. PMID: 18383132.

5. California environmental protection agency, Propose identification of environmental 
tobacco smoke, as a toxic air contaminant, June 2005.

6. Burke Het al. Prenatal and passive smoke exposure and incidence of asthma and wheeze: Systematic review and metaanalysis. Pediatrics 129:735-744, 2012

7. Wang MFet al. Exposure to environmental tobacco smoke, human E-cadherin C-160A polymorphism, and childhood asthma. Ann Allergy Asthma Immunol 111:262-267, 2013

8. He QQ et al. Environmental tobacco smoke exposure and Chinese schoolchildren's respiratory health: A prospective cohort study. Am J Prev Med 41:487-493, 2011.

9. Nuhoglu $\mathrm{C}$ et al, Effects of passive smoking on lung function in children, Pediatr Int. 2003 Aug;45(4):426-8.

10. Hogg JC et al, Lung structure and function in cigarette smokers. Thorax 1994;49:47378.

11. Alan Smyth et al, Passive smoking and impaired lung function in cystic fibrosis.; Archives of disease in Childhood,1994;71: 353:354

12. Xu X, Li BL, Wang LH. Gender difference in smoking effects on adult pulmonary function. Eur respire J,1994.

13. MM Haby, JK Peat, AJ Woolcock, Effect of passive smoking, asthma, and respiratory infection on lung function in Australia, PediatrPulmonol (1994) 18: 323-9

14. Corbo GM et al, Parental smoking and lung function: Misclassification due to background exposure to passive smoking. Respir Med 2007; 101:768-73.

15. Corbo, GM, Passive smoking and lung function in [alpha] 1-antitrypsin heterozygote school children,, Paediatrics Thorax. 58(3):237-241, March 2003.

16. Sherrill DLet al, Longitudinal effects of passive smoking on pulmonary function in
New Zealand children. Am Rev Respir Dis. 1992 May;145(5):1136-41

17. Brusasco V, Pellegrino R, Functional classification of COPD. Eur Respir Rev 2002, 12:284-286.

18. International Consultation on Environmental Tobacco Smoke (ETS) and Child Health, 11-14 January 1999, Geneva, Switzerland. Consultation Report (document

19. Kim CS, Hu SC, Regional deposition of inhaled particles in human lungs: comparison between men and women. J ApplPhysiol 1998, 84:1834-1844.

20. Becklake MR, Kauffmann F, Gender differences in airway behaviour over the human life span. Thorax 1999, 54:11191138.

21. Mead J Dysanapsis in normal lungs assessed by the relationship between maximal flow, static recoil, and vital capacity. Am Rev Respir Dis 1980, 121:339-342

22. Bek K, Tomaç N, Delibas A, Tuna F, Teziç HT, Sungur M. The effect of passive smoking on pulmonary function during childhood. Postgrad Med J. 1999 Jun;75(884):339-41. doi: 10.1136/pgmj.75.884.339. PMID: 10435167; PMCID: PMC1741251.

23. Nancy NR, Rai UC. A study of forced expiratory spirogram in south Indian beedi smokers and cigarette smokers. Ind J Chest Diseases \& Allied Sci 1981; 31:25-30.

24. Mehmet Polatlý, The Early Effect of Smoking on Spirometry and Transfer Factor, Turkish Respiratory Journal, December 2000, Vol.1, No.2

How to cite this article: Sutaria T, Talati N, Vaghasiya A et.al. Relationship between parental smoking and children's pulmonary function. International Journal of Science \& Healthcare Research. 2021; 6(4): 293-298. DOI: https://doi.org/10.52403/ijshr.20211041 